Check for updates

Cite this: Mater. Adv., 2020 1,1920

Received 25th June 2020 Accepted 27th July 2020

DOI: $10.1039 / \mathrm{d} 0 \mathrm{ma} 00452 \mathrm{a}$

rsc.li/materials-advances

\title{
The properties, photovoltaic performance and stability of visible to near-IR all inorganic perovskites $\dagger$
}

\author{
Adva Shpatz Dayan, ${ }^{a}$ Xinjue Zhong, (D) ${ }^{b}$ Małgorzata Wierzbowska, (D) \\ C. E. M. de Oliveira, ${ }^{d}$ Antoine Kahn (1D ${ }^{b}$ and Lioz Etgar (1D *a
}

\begin{abstract}
Hybrid metal halide perovskites have seen an exponential increase in the scientific community due to their successful introduction in solar cells. However, these materials are known to suffer from thermal instability, toxicity and limited absorption range. One way to overcome these obstacles is by substituting the organic cation with an inorganic one and by replacing the lead with tin, which can shift the absorbance to the near infra-red (NIR). In this work we synthesized several compositions of all inorganic $\left.\mathrm{CsSn}_{y} \mathrm{~Pb}_{1-y} \mathrm{Br}_{x}\right|_{3-x}(0 \leq y \leq 1,0 \leq x \leq 3)$ perovskites, achieving a wide band gap range from $1.3 \mathrm{eV}$ to $1.75 \mathrm{eV}$. It was found that $\mathrm{Sn}$ stabilizes the $\mathrm{CsPb}_{3}$ black photovoltaic (PV) active phase and at the same time shifts the absorbance to the NIR. Although some of these perovskite compositions are already known, here we analyzed in detail their physical and electronic properties. Hall effect measurements show an increase in the carrier concentration and Hall mobility with the addition of Sn. Interestingly, the Hall mobility is five times higher for $\mathrm{CsSnl}_{3}$ than in the case of having just $10 \% \mathrm{~Pb}$ and $90 \% \mathrm{Sn}$ in the perovskite structure. Ultraviolet photoemission spectroscopy (UPS) and density functional theory (DFT) calculations reveal the energy level position and phase mixing, which explain the reduction in the photovoltaic performance with the addition of Sn. The best PV performance of $12.7 \%$ efficiency was achieved in the case of an $80: 20 \mathrm{~Pb}: \mathrm{Sn}$ ratio, which is one of the highest PCEs reported for similar perovskite compositions.
\end{abstract}

\section{Introduction}

Organic-inorganic perovskites are being used today in a variety of optoelectronic applications. Hybrid perovskites have several unique properties which make them attractive semiconductors for use in the photovoltaic (PV) field. ${ }^{1-3}$ In order for the perovskite to function efficiently as a light harvester in the solar cell, it must be stable under environmental conditions (especially moisture $)^{4-6}$ and have high photostability for long term use. ${ }^{7-9}$

The general formula of basic halide perovskites is $\mathrm{ABX}_{3}$ where A is generally an organic cation (methylammonium $\mathrm{MA}^{+}$, formamidinium $-\mathrm{FA}^{+}$) but can be also an inorganic cation

\footnotetext{
${ }^{a}$ Institute of Chemistry, Casali Center for Applied Chemistry, The Hebrew University of Jerusalem, Jerusalem 91904, Israel. E-mail: lioz.etgar@mail.huji.ac.il

${ }^{b}$ Department of Electrical Engineering, Princeton University, Princeton, New Jersey 08544, USA

${ }^{c}$ Institute of High Pressure Physics, Polish Academy of Sciences Sokolowska 29/37, 01-142 Warsaw, Poland

${ }^{d}$ The Center for Nanoscience and Nanotechnology, The Hebrew University of Jerusalem, Jerusalem 91904, Israel

$\dagger$ Electronic supplementary information (ESI) available. See DOI: 10.1039/d0ma00452a
}

$\left(\mathrm{Cs}^{+}\right)$; $\mathrm{B}$ is a divalent metal cation $\left(\mathrm{Pb}^{2+}, \mathrm{Sn}^{2+}, \mathrm{Ge}^{2+}, \mathrm{Sr}^{2+}\right.$, and $\left.\mathrm{Cu}^{2+}\right)^{10-13}$ and $\mathrm{X}$ is a halide anion $\left(\mathrm{Cl}^{-}, \mathrm{Br}^{-}, \mathrm{I}^{-}\right)$.

The common hybrid perovskite used in solar cells over the past few years is $\mathrm{CH}_{3} \mathrm{NH}_{3} \mathrm{PbI}_{3}\left(\mathrm{MAPbI}_{3}\right)$. However, this material has an organic cation (usually $\mathrm{MA}^{+}$) which makes the entire structure relatively unstable under high temperature. ${ }^{14-16}$ Moreover, the use of $\mathrm{Pb}$ as the divalent cation is problematic due to its toxicity. ${ }^{17-19}$ Several reports show that the replacement of the organic cation by an inorganic cation can improve the stability of the perovskite. ${ }^{20-26}$ Following this direction, one of the potential candidates is $\mathrm{CsPbI}_{3}$, which has an absorbance onset around $700 \mathrm{~nm}$. $\mathrm{CsPbI}_{3}$ has four phases: $\alpha, \beta, \gamma$ and $\delta$, but only $\alpha$ and $\beta$ can be used in PV solar cells, while $\gamma$ and $\delta$ are metastable phases that are inactive in PV cells. ${ }^{27}$ The transition between the phases usually happens due to exposure to air when the $\alpha$ phase, which is cubic, transforms to the $\beta$ phase (tetragonal structure) and then to the $\gamma$ and $\delta$ phases (orthorhombic structure). In our previous report, we showed that $\mathrm{CsPbI}_{3}$ can be stabilized in a two dimensional structure (2D); ${ }^{28}$ however, it forms a wide band gap, which makes it problematic to function efficiently in a solar cell. ${ }^{29}$ Other methods to stabilize the $\mathrm{CsPbI}_{3}$ active phase include the addition of different salts such as $\mathrm{EuBr}_{2}, \mathrm{EuCl}_{2}$, and $\mathrm{CaI}_{2}{ }^{25-31}$ 
Modifying the $\mathrm{B}$ site in $\mathrm{CsPbI}_{3}$ can tune the optical properties and at the same time can enhance its stability. The replacement of lead $(\mathrm{Pb})$ by tin $(\mathrm{Sn})$ in the case of $\mathrm{MA}^{+}$based perovskites leads to a variation in the band gap from $1.55 \mathrm{eV}$ for $\mathrm{MAPbI}_{3}$ to $1.3 \mathrm{eV}$ for $\mathrm{MASnI}_{3} \cdot{ }^{32-35}$ Replacing $\mathrm{Pb}$ with $\mathrm{Sn}$ in the case of a fully inorganic perovskite (Cs based perovskite) might assist in getting a stable structure and at the same time will shift the absorbance to the near-IR. Moreover, introducing Sn instead of $\mathrm{Pb}$ will reduce the toxicity of the perovskite.

In order for another element to be able to replace $\mathrm{Pb}^{2+}$ in the perovskite structure, it needs to have a coordination number equal to six and a similar ionic radius. An additional indication can be obtained from the Goldschmidt tolerance factor (eqn (1)), where $r_{\mathrm{A}}$ is the radius of the A cation, $r_{\mathrm{B}}$ is the radius of the $\mathrm{B}$ cation, and $r_{\mathrm{X}}$ is the radius of the anion.

$$
t=\frac{r_{\mathrm{A}}+r_{\mathrm{X}}}{\sqrt{2}\left(r_{\mathrm{B}}+r_{\mathrm{X}}\right)}
$$

The ionic radius of $\mathrm{Sn}^{2+}$ is smaller than that of $\mathrm{Pb}^{2+} ; 3$ therefore, when introducing more $\mathrm{Sn}^{2+}$ instead of $\mathrm{Pb}^{2+}$, the tolerance factor increases and as a result we observe a perovskite which has a stable structure compared to $\mathrm{CsPbI}_{3} \cdot{ }^{37,38}$ In addition, the Sn-I bond length is shorter than the Pb-I bond length, which supports a stable structure in the case of Snbased perovskites.

The radius of the inorganic cation $\left(\mathrm{Cs}^{+}\right)$is smaller than that of $\mathrm{MA}^{+}$, which suggests further enhancement in the stability of the structure. ${ }^{39} \mathrm{CsSnI}_{3}$ was demonstrated first in 2012 by Chung et al. ${ }^{40}$ who used it as a hole transport material (HTM) in dye-sensitized solar cells. ${ }^{41}$ In 2016 Wang et al. studied $\mathrm{CsSnI}_{3}$ as the light harvester material in a solar cell and reported an efficiency of $3.31 \% .{ }^{42}$ The combination of $\mathrm{Sn}$ and $\mathrm{Pb}$ in the solar cell was reported using organic cations $\left(\mathrm{MA}^{+}\right.$and $\mathrm{FA}^{+}$), achieving a power conversion efficiency (PCE) of 15\%. In addition, in 2015 Sabba et al. published their work using $\mathrm{CsSnI}_{2.9} \mathrm{Br}_{0.1}$ as a light harvester material in a solar cell and achieved a low PCE of $1.67 \%{ }^{40}$ Other reports demonstrate the use of bromide and mixed halides with solely $\mathrm{Sn}$ in solar cells. $^{43-45}$

Liu et al. synthesized $\operatorname{CsSn}_{1-x} \mathrm{~Pb}_{x} \mathrm{I}_{3}$ and $\mathrm{CsSn}_{1-x} \mathrm{~Pb}_{x} \mathrm{Br}_{2} \mathrm{I}$ nanocrystals and used them in light emitting diode devices. ${ }^{46}$ In 2017 Liang et al. used all inorganic perovskites with mixed halides (Br, I). ${ }^{47}$ In this study they used $\mathrm{CsPbBr}_{3}, \mathrm{CsPbIBr}_{2}$ and a specific composition $\mathrm{CsPb}_{0.9} \mathrm{Sn}_{0.1} \mathrm{IBr}_{2}$ (where the amount of Sn is no more than $10 \%$ ), and demonstrated a PCE of $11.33 \%$. A year later $\mathrm{Li}$ et al. used the $\mathrm{CsPb}_{0.75} \mathrm{Sn}_{0.25} \mathrm{IBr}_{2}$ perovskite (keeping the ratio between the halides constant), achieving a slightly higher PCE of $11.53 \% .^{48}$

Although these compositions were already discussed in the literature, here we shed light on their physical, stability and electronic properties using Hall effect measurements and ultraviolet photoelectron spectroscopy (UPS). We combine an inorganic cation (i.e. $\mathrm{Cs}^{+}$) with $\mathrm{Pb}$ and $\mathrm{Sn}$ at the $\mathrm{B}$ site of the perovskite. We synthesize and study materials using various ratios of $\mathrm{Sn}$ and $\mathrm{Pb}$ based on the chemical formula $\mathrm{CsSn}_{y} \mathrm{~Pb}_{1-y} \mathrm{Br}_{x} \mathrm{I}_{3-x}$ (Table 1). As a result we were able to achieve
Table 1 Perovskite compositions studied in this work, $\mathrm{CsSn}_{y} \mathrm{~Pb}_{1-y} \mathrm{Br}_{x} \mathrm{I}_{3-x}$ $(0 \leq y \leq 1,0 \leq x \leq 3)$

\begin{tabular}{ll}
\hline $\mathrm{Pb}:$ Sn ratio & Perovskite composition \\
\hline $100: 0$ & $\mathrm{CsPbI}_{3}$ \\
$90: 10$ & $\mathrm{CsSn}_{0.1} \mathrm{~Pb}_{0.9} \mathrm{I}_{2.8} \mathrm{Br}_{0.2}$ \\
$80: 20$ & $\mathrm{CsSn}_{0.2} \mathrm{~Pb}_{0.8} \mathrm{I}_{2.6} \mathrm{Br}_{0.4}$ \\
$70: 30$ & $\mathrm{CsSn}_{0.3} \mathrm{~Pb}_{0.7} \mathrm{I}_{2.4} \mathrm{Br}_{0.6}$ \\
$60: 40$ & $\mathrm{CsSn}_{0.4} \mathrm{~Pb}_{0.6} \mathrm{I}_{2.2} \mathrm{Br}_{0.8}$ \\
$50: 50$ & $\mathrm{CsSn}_{0.5} \mathrm{~Pb}_{0.5} \mathrm{I}_{2} \mathrm{Br}_{1}$ \\
$40: 60$ & $\mathrm{CsSn}_{0.6} \mathrm{~Pb}_{0.4} \mathrm{I}_{1.8} \mathrm{Br}_{1.2}$ \\
$30: 70$ & $\mathrm{CsSn}_{0.7} \mathrm{~Pb}_{0.3} \mathrm{I}_{1.6} \mathrm{Br}_{1.4}$ \\
$20: 80$ & $\mathrm{CsSn}_{0.8} \mathrm{~Pb}_{0.2} \mathrm{I}_{1.4} \mathrm{Br}_{1.6}$ \\
$10: 90$ & $\mathrm{CsSn}_{0.9} \mathrm{~Pb}_{0.1} \mathrm{I}_{1.2} \mathrm{Br}_{1.8}$ \\
$0: 100$ & $\mathrm{CsSnI}_{3}$ \\
\hline
\end{tabular}

a wide range of band gaps from $1.3 \mathrm{eV}$ to $1.75 \mathrm{eV}$. The Hall effect and UPS measurements reveal the hole mobility, carrier density and the energy level position of this fully inorganic perovskite. The stability under humidity and photostability of these compositions as films and full devices are also studied. Finally, we demonstrate the application of these compositions in mesoporous perovskite based solar cells, achieving one of the highest efficiencies reported for $\mathrm{CsSn}_{y} \mathrm{~Pb}_{1-y} \mathrm{Br}_{x} \mathrm{I}_{3-x}$ perovskites.

\section{Results and discussion}

Introducing $\mathrm{Sn}$ (instead of $\mathrm{Pb}$ ) into the perovskite structure can lead to four different phases, as in the case of $\mathrm{CsPbI}_{3}$, with some of them being PV active. Since $\mathrm{Cs}^{+}$is used as the cation, it occupies the $1 \mathrm{~b}$ Wyckoff position in the center of the perovskite cube, and therefore it is easier to create the ideal cubic $P m \overline{3} m$ structure than in the case of most organic cations.

Our motivation here was to find a way to stabilize the active $\mathrm{CsPbI}_{3}$ phase. Here we used the $\mathrm{Sn}^{2+}$ cation in addition to the $\mathrm{Pb}^{2+}$ cation in order to create a good overlap between the orbitals of the divalent metal cation $\left(\mathrm{Pb}^{2+}\right.$ and $\left.\mathrm{Sn}^{2+}\right)$ and the orbitals of the halide anion $\left(\mathrm{I}^{-}, \mathrm{Br}^{-}\right)$. The band gap of these semiconductors is determined by the orbitals of the halide and the divalent metal cation. ${ }^{49}$ It is known that the valence-band maximum (VBM) is predominantly determined by the antibonding component of the hybridization between the divalent metal in the $\mathrm{B}$ site and the halide in the $\mathrm{X}$ site, while the conduction-band minimum (CBM) is dominated by the nonbonding component of the divalent metal. In the case of $\mathrm{Pb}$ halides, the overlap of $\mathrm{Pb}-\mathrm{I} / \mathrm{Br}$ is between the $6 \mathrm{~s}$ orbital of $\mathrm{Pb}^{2+}$ and the $5 \mathrm{p}$ or $4 \mathrm{p}$ orbital of $\mathrm{I}^{-}$or $\mathrm{Br}^{-}$, respectively. The $6 \mathrm{~s}$ and $6 \mathrm{p}$ orbitals of $\mathrm{Pb}$ are at a higher binding energy compared to the $5 \mathrm{~s}$ and $5 \mathrm{p}$ orbitals of $\mathrm{Sn}$, and as a result the binding energy of the $\mathrm{s}-\mathrm{p}$ hybridized antibonding levels is lower for $\mathrm{Sn}(5 \mathrm{~s})$ and $(5 \mathrm{p})-\mathrm{X}(\mathrm{p})$ than for $\mathrm{Pb}(6 \mathrm{~s})$ and $(6 \mathrm{p})-\mathrm{X}(\mathrm{p})$. As a consequence, both the VBM and CBM undergo an upshift when $\mathrm{Sn}$ replaces $\mathrm{Pb} .^{50}$

Fig. 1a and $\mathrm{b}$ show the absorbance as a function of $\mathrm{Sn}$ concentration in the $\mathrm{CsSn}_{y} \mathrm{~Pb}_{1-y} \mathrm{Br}_{x} \mathrm{I}_{3-x}$ perovskite structure. The absorption edge shifts to longer wavelength and extends to the Near Infra-Red (NIR) region with increasing Sn concentration. Similar bandgap changes have been observed in $\mathrm{MASn}_{x} \mathrm{~Pb}_{1-x} \mathrm{I}_{3}{ }^{32}$ 

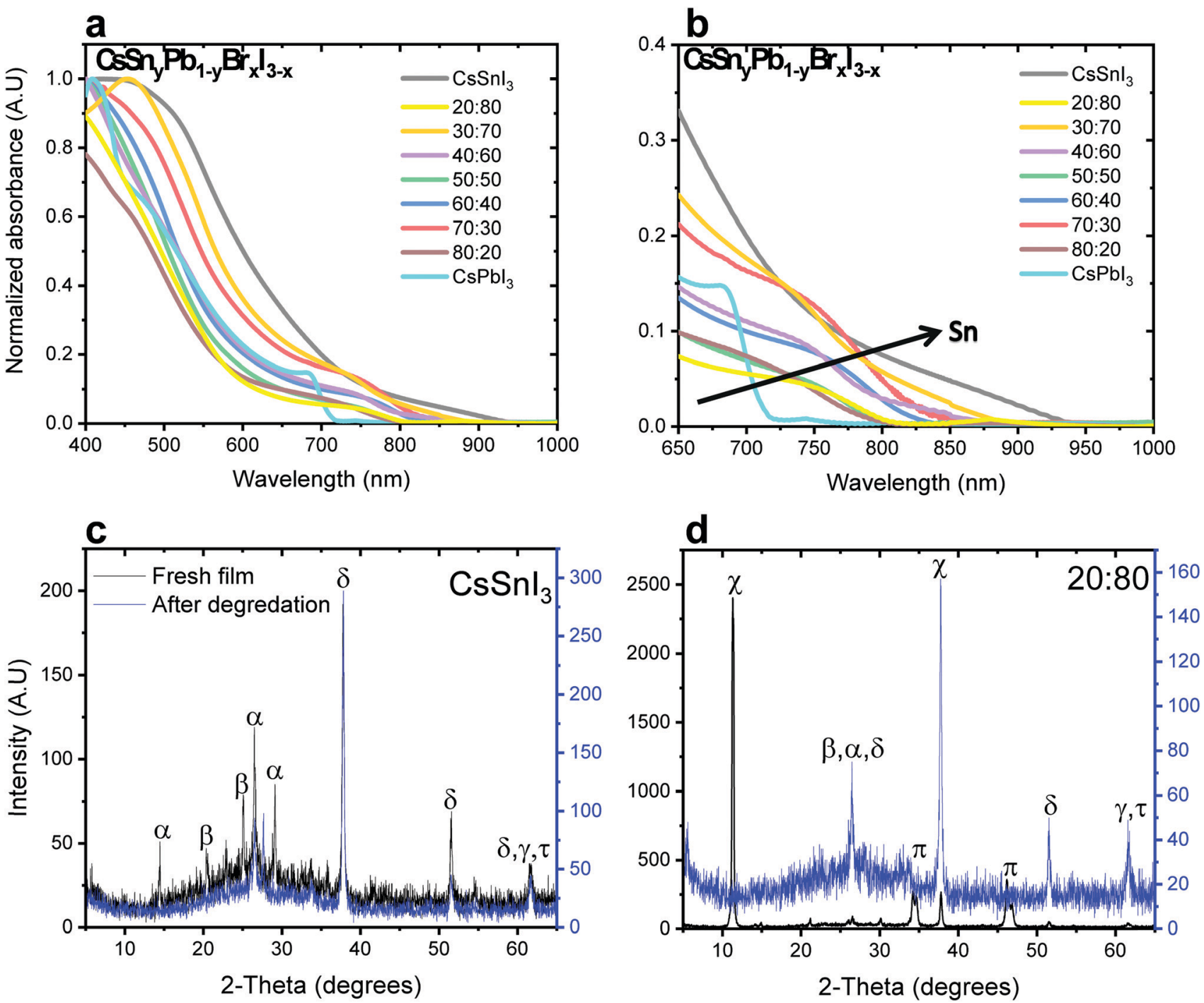

Fig. 1 (a) Absorbance spectra of $\mathrm{CsSn}_{y} \mathrm{~Pb}_{1-y} \mathrm{Br}_{x} \mathrm{I}_{3-x}(0 \leq y \leq 1,0 \leq x \leq 3)$ films encapsulated at different ratios of $\mathrm{Pb}$ : Sn. (b) Magnification of the absorbance spectra (shown in (a)) in the range of 650-1000 nm. XRD patterns of (c) CsSnl ${ }_{3}$ and (d) $\mathrm{CsSn}_{0.8} \mathrm{~Pb}_{0.2} \mathrm{I}_{1.4} \mathrm{Br}_{1.6}(\mathrm{~Pb}: \mathrm{Sn}-20: 80$ ) before and after degradation. ( $\pi-\mathrm{CsPbl}_{3}$ cubic phase, $\chi-\mathrm{CsPbl}_{3}$ orthorhombic phase, $\alpha-\mathrm{CsSnl}_{3}, \delta-\mathrm{SnO}_{2}, \beta-\mathrm{Snl}_{2}, \gamma-\mathrm{Pbl}_{2}, \tau-\mathrm{Csl}_{\text {.) }}$

In order to compare the influence of the B site (i.e. Sn vs. $\mathrm{Pb}$ ) to that of the $\mathrm{X}$ site (i.e. I vs. Br) on the optical properties, we synthesized $\mathrm{CsSn}_{y} \mathrm{~Pb}_{1-y} \mathrm{I}_{3}$ and $\mathrm{CsSn}_{y} \mathrm{~Pb}_{1-y} \mathrm{Br}_{x} \mathrm{I}_{3-x}(0 \leq y \leq 1$, $0 \leq x \leq 3)$. In the synthesis of $\mathrm{CsSn}_{y} \mathrm{~Pb}_{1-y} \mathrm{Br}_{x} \mathrm{I}_{3-x}$ the bromide has one source, i.e., $\mathrm{SnBr}_{2}$, whereas the iodide has two sources, $\mathrm{PbI}_{2}$ and CsI.

Fig. 2a shows the band gap as a function of the $\mathrm{Pb}: \mathrm{Sn}$ ratios in both cases of mixed bromide-iodide and pure iodide. As was discussed above, the band gap decreases with the addition of $\mathrm{Sn}$. Moreover, the influence of the bromide on the band gap is also observed. The change in the band gap is more pronounced in the case of pure iodide compare to the case of mixed iodidebromide. The bromide shifts the absorbance to shorter wavelength, which compensates slightly for the red shift due to the addition of Sn. This can be explained when looking at the slope of the curves in Fig. 2a. The slope of the green dots (pure iodide) is larger by 1.5 times than the slope of the blue dots (mixed bromide-iodide). All the absorbance spectra can be seen in Fig. S1 and S3 (ESI $\dagger$ ). Therefore, we can suggest that the influence of Sn on the band gap is more pronounced than that of bromide in this case. We were able to achieve a wide range of band gaps from $1.3 \mathrm{eV}$ to $1.75 \mathrm{eV}$.

$\mathrm{X}$-ray diffraction (XRD) measurements were performed for different ratios of $\mathrm{Pb}: \mathrm{Sn}$. Fig. $1 \mathrm{c}$ and d show the cases of pure $\mathrm{CsSnI}_{3}$ and $\mathrm{CsSn}_{y} \mathrm{~Pb}_{1-y} \mathrm{Br}_{x} \mathrm{I}_{3-x}$ with a $20: 80 \mathrm{~Pb}: \mathrm{Sn}$ ratio, respectively. (Other $\mathrm{Pb}: \mathrm{Sn}$ ratios are presented in the ESI, $\dagger$ in Fig. S2.) The black curve corresponds to the fresh film, while the blue curve corresponds to the film after degradation. In our previous work we found that after 48 hours at room conditions (ambient air) full degradation is observed. ${ }^{28}$ We determine full degradation of the perovskite by absorbance and XRD measurements, which indicate the presence of the material's precursors (mainly $\mathrm{PbI}_{2}$ and CsI). Fig. 1c exhibits peaks related to $\mathrm{CsSnI}_{3}$ $\left(2 \theta=14,27,29^{\circ}\right)$ and $\operatorname{SnI}_{2}\left(2 \theta=22,28^{\circ}\right)$, where peaks related to 

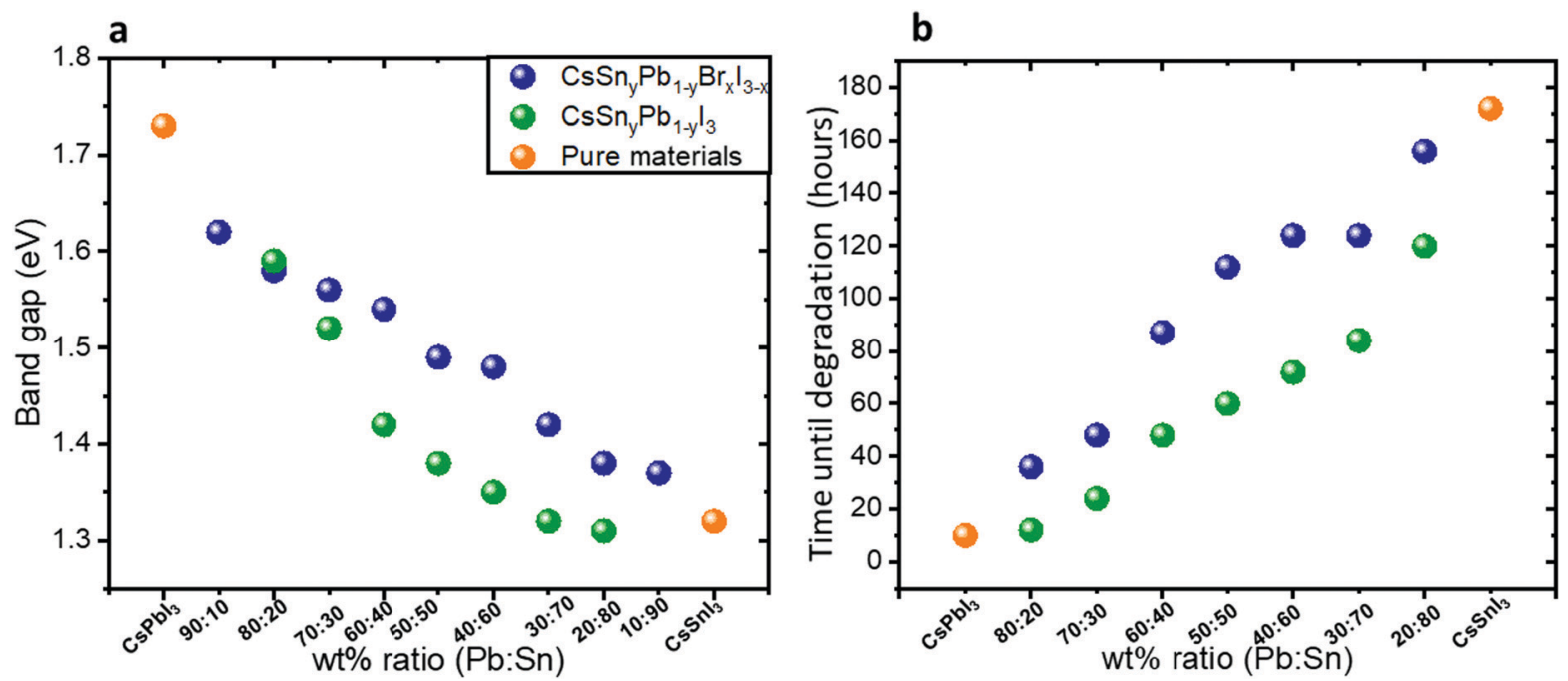

Fig. 2 (a) The band gap as a function of the $\mathrm{Pb}: \mathrm{Sn}$ ratio for the cases of mixed iodide and bromide and for pure iodide compounds. The slope of the green dots is 1.5 times larger than the slope of the blue dots. (b) Photostability measurements under 1 sun illumination, $18{ }^{\circ} \mathrm{C}$ and $27 \%$ humidity. The data in this graph are based on the absorbance spectra shown in Fig. S4 and S5 (ESI†).

$\mathrm{SnO}_{2}\left(2 \theta=39,62^{\circ}\right)$ can be observed just after degradation due to the Sn oxidation. The spectrum for a $20: 80 \mathrm{~Pb}: \mathrm{Sn}$ ratio can be seen in Fig. 1d, where the cubic and the orthorhombic phases of $\mathrm{CsPbI}_{3}$ can be observed. After degradation, the perovskite dissociates into $\mathrm{SnI}_{2}, \mathrm{PbI}_{2}$ and CsI. The presence of $\mathrm{CsPbI}_{3}$ in the fresh film suggests that both $\mathrm{CsPbI}_{3}$ and $\mathrm{CsSnI}_{3}$ are formed.

Photostability measurements on the synthesized hybrid $\mathrm{CsSn}_{y} \mathrm{~Pb}_{1-y} \mathrm{Br}_{x} \mathrm{I}_{3-x}$ and $\mathrm{CsSn}_{y} \mathrm{~Pb}_{1-y} \mathrm{I}_{3}$ were performed under continuous 1 sun illumination, $18{ }^{\circ} \mathrm{C}$ and $27 \%$ humidity. Fig. 2b summarizes these measurements for different $\mathrm{Pb}: \mathrm{Sn}$ ratios. For each ratio we followed the absorbance spectra as a function of time. The corresponding absorbance spectra are presented in Fig. S4 and S5 (ESI $\dagger$ ). It can be seen clearly that as the Sn amount increases, the photostability of the perovskite increases. For example, at a $\mathrm{Pb}: \mathrm{Sn}$ ratio of $20: 80$, the perovskite does not degrade for 172 hours under continuous 1 sun illumination, $18{ }^{\circ} \mathrm{C}$ and $27 \%$ humidity. Interestingly, even in the case of $20 \% \mathrm{Sn}$ in the perovskite structure, the photostability improved notably compared to pure $\mathrm{CsPbI}_{3}$. An important observation from these measurements is that the mixed halide (iodide and bromide) perovskite is more photostable than the single halide (i.e. iodide) perovskite in the structure. Based on this fact, the rest of the work concentrates on the mixed halide perovskite. Scanning electron microscopy (SEM) micrographs of the films before and after degradation (48 hours) are presented in Fig. S6 (ESI $\dagger)$. After degradation there are more pinholes and the grain boundaries are better defined than in the case of fresh films.

Following the photostability measurements, we explored the stability of the different samples under room conditions and without encapsulation. The photographs of the films as a function of time are shown in Fig. S7 and S8 (ESI $\dagger$ ). Similar to the case of the photostability measurements, when the ratio of $\mathrm{Sn}: \mathrm{Pb}$ is higher, the perovskite is more stable in air without encapsulation. It can be seen that $\mathrm{CsSnI}_{3}$ is stable in air for over 48 hours. Similar to the photostability measurements, films with $\mathrm{Pb}:$ Sn ratios of $20: 80,30: 70$ and $40: 60$ showed excellent stability for over 24 hours. It is important to keep in mind that $\mathrm{CsPbI}_{3}$ cannot survive more than $10 \mathrm{~min}$ in air. ${ }^{28}$ These experiments (photostability and stability) indicate clearly that the resistance of the perovskite to humidity is enhanced when $\mathrm{Pb}$ is replaced by Sn. This enhanced stability is in contrast to the case of the perovskite with mixed $\mathrm{Pb}$ and $\mathrm{Sn}$ having an organic cation at the A site. In this case the stability decreases by more than $50 \%$ when introducing $\mathrm{Sn}$ into the perovskite. ${ }^{51}$ In our case (see Fig. 3), since Cs is used as the inorganic cation at the A site, the lattice parameter is reduced and the cubic structure shrinks compared to the case of an organic cation, which changes the tolerance factor, and this slows down the oxidation reaction of Sn and provides enhanced stability. ${ }^{51}$ In addition to that effect, it was found that mixed halide perovskites (iodide and bromide) have better stability than single halide (iodide) perovskites. ${ }^{52}$

In order to study the hole mobility, carrier concentration and resistivity for the various $\mathrm{Pb}$ : $\mathrm{Sn}$ ratios, Hall effect measurements were performed. When a magnetic field is applied on a conductor or a semiconductor that carries an electric current, a potential difference across the sample and perpendicular to both the current and the magnetic field will be developed. This is called the Hall effect, and the potential difference developed across the sample is the Hall voltage $\left(V_{\mathrm{H}}\right)$. By measuring the Hall voltage, it is possible to get the $n q$ product, the mobile carrier density multiplied by the charge of carriers $(n-$ electron density, $q$ - charge of carriers). Several studies showed the use of Hall effect measurements to reveal the properties of $2 \mathrm{D}$ materials such as black phosphorene. ${ }^{53,54}$

Hall effect measurements were performed on perovskite films deposited on microscope glass substrates with four gold contacts at the corners. It can be observed in Fig. $4 \mathrm{a}-\mathrm{c}$ that, 


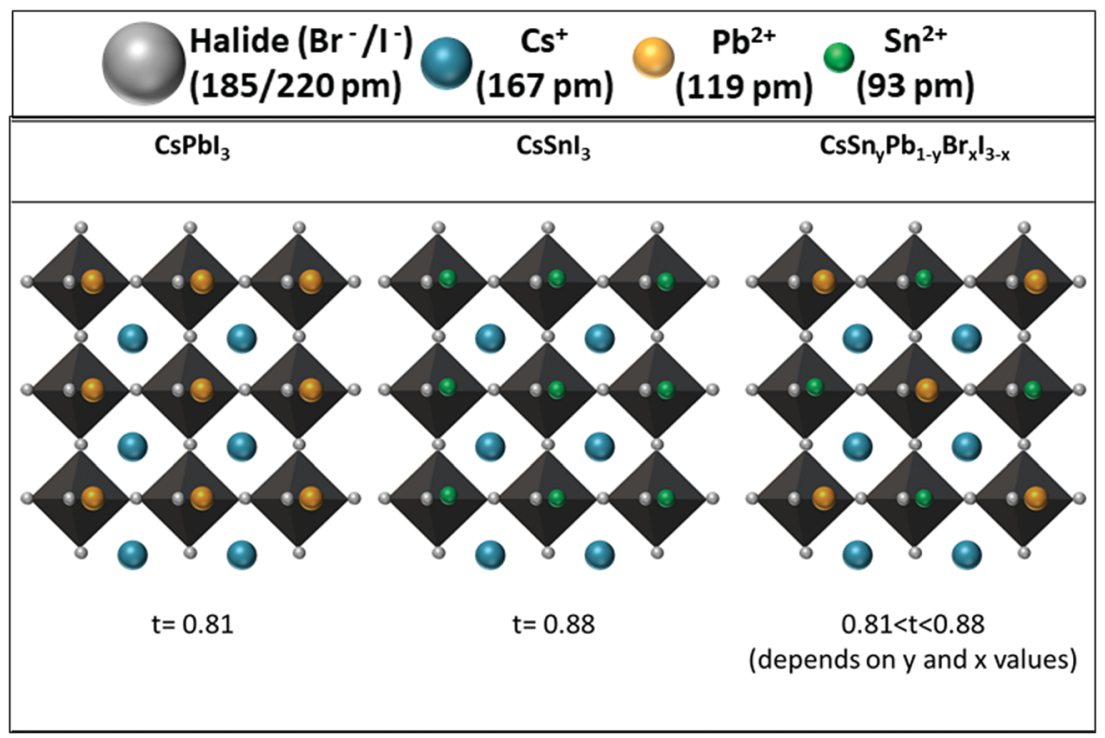

Fig. 3 Schematic illustration of the change in the tolerance factor as a result of $\mathrm{Cs}, \mathrm{Pb}$ and $\mathrm{Sn}$ in the perovskite structure.
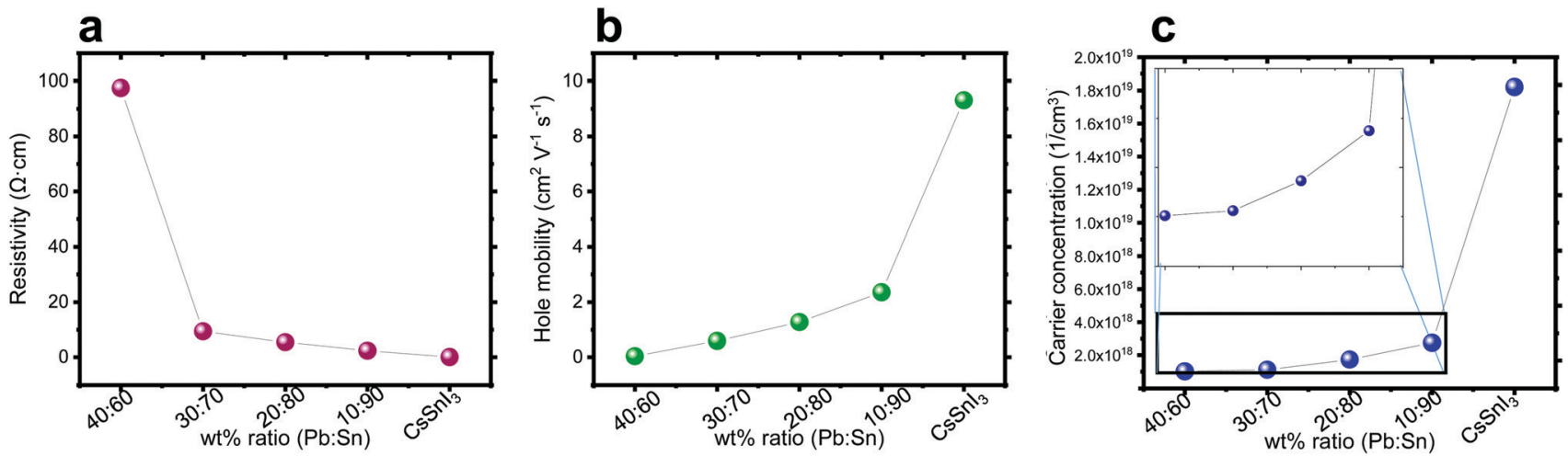

Fig. 4 Hall effect measurement of the different ratios $\mathrm{Pb}: \mathrm{Sn}$ : (a) resistivity, (b) hole mobility, and (c) carrier concentration.

as the amount of Sn increases, the carrier concentration and the mobility increase, while the resistivity decreases. This trend can be explained by the oxidization of $\mathrm{Sn}$. It is known that $\mathrm{Sn}^{2+}$ oxidizes easily in an ambient atmosphere to $\mathrm{Sn}^{4+} .51$ The replacement of $\mathrm{Sn}^{2+}$ by $\mathrm{Sn}^{4+}$ in the perovskite structure has been linked to hole doping, which increases the number of carriers ${ }^{55}$ and can explain the decrease in resistivity as shown in Fig. 4a. As the $\mathrm{Pb}: \mathrm{Sn}$ ratio increases, there is more $\mathrm{Sn}$ in the structure, which potentially can be oxidized, and Fig. 4 shows that the carrier concentration, hole mobility and resistivity change as a function of this ratio.

The carrier type determines the semiconductor type. The Hall effect measurement can assist in determining the type of these semiconductors. It was observed that with the addition of $\mathrm{Pb}$ into the perovskite structure the behavior of the film is becoming less p-type. In general, doping the structure with $\mathrm{Pb}$ influences dramatically the properties (mobility, carrier concentration and resistivity) compared to a perovskite which is solely based on $\mathrm{Sn}$.

The energy levels of films with different ratios of $\mathrm{Pb}: \mathrm{Sn}$ were measured by ultraviolet photoemission spectroscopy (UPS).
The perovskite films were spin-coated on conductive indium tin oxide (ITO)/glass substrates. Fig. 5a and b show the photoemission cut-off and the VBM, respectively, measured on $\mathrm{CsSn}_{0.2} \mathrm{~Pb}_{0.8} \mathrm{I}_{2.6} \mathrm{Br}_{0.4}$. The cut-off position yields a work function of $4.77 \mathrm{eV}$. The valence band spectrum, recorded and plotted on a logarithmic scale, shows the VBM at $0.89 \mathrm{eV}$ below the Fermi level ( $0 \mathrm{eV}$ on the energy scale). The ionization energy (IE) of this film $(\mathrm{Pb}: \mathrm{Sn}-80: 20)$ is therefore $5.66 \mathrm{eV}$. Measurements on films with various $\mathrm{Pb}: \mathrm{Sn}$ ratios show that the IE decreases to $5.64 \mathrm{eV}$ for $70: 30,5.56 \mathrm{eV}$ for $60: 40$, and finally to $5.37 \mathrm{eV}$ for 20:80 (see Fig. S9, ESI $\dagger$ ). By combining the optical bandgap and the VBM position, the position of the CBM can be estimated, assuming that the exciton binding energy is small and negligible with respect to the photoemission resolution in 3D perovskites. ${ }^{56-58}$ The CBM shifts to higher energy with increasing $\mathrm{Sn}^{2+}$ concentration, following the trend of the VBM, as shown in Fig. 5c. The IE of $\mathrm{CsPbI}_{3}$ is higher than expected, mainly due to the fast degradation of the film during sample transfer. It has been reported ${ }^{50,59}$ that the VBM arises from antibonding hybridization of $\mathrm{Pb}(6 \mathrm{~s})$ and/or $\mathrm{Sn}(5 \mathrm{~s})$ and 
a

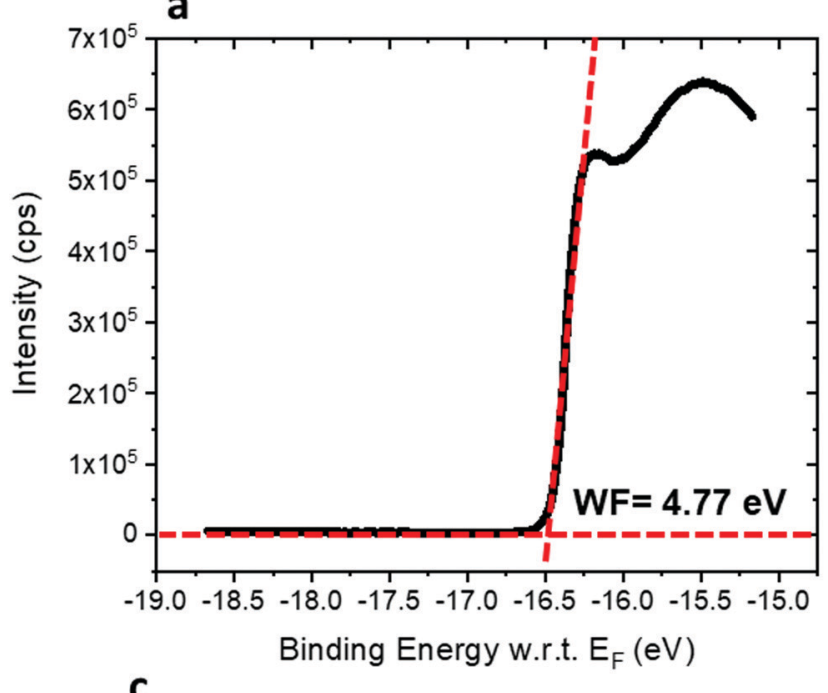

C

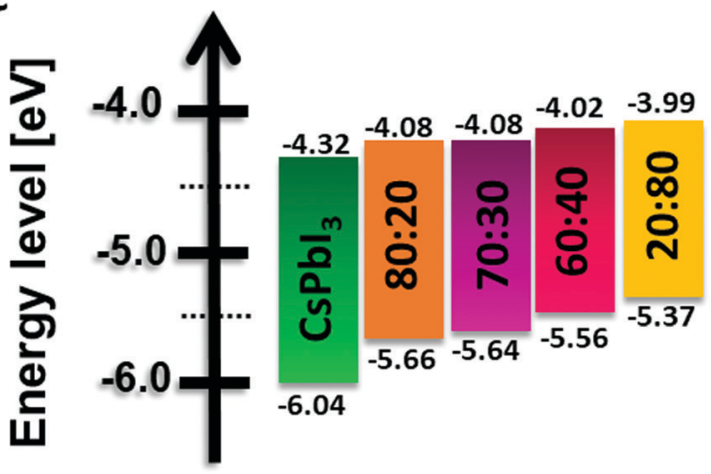

b
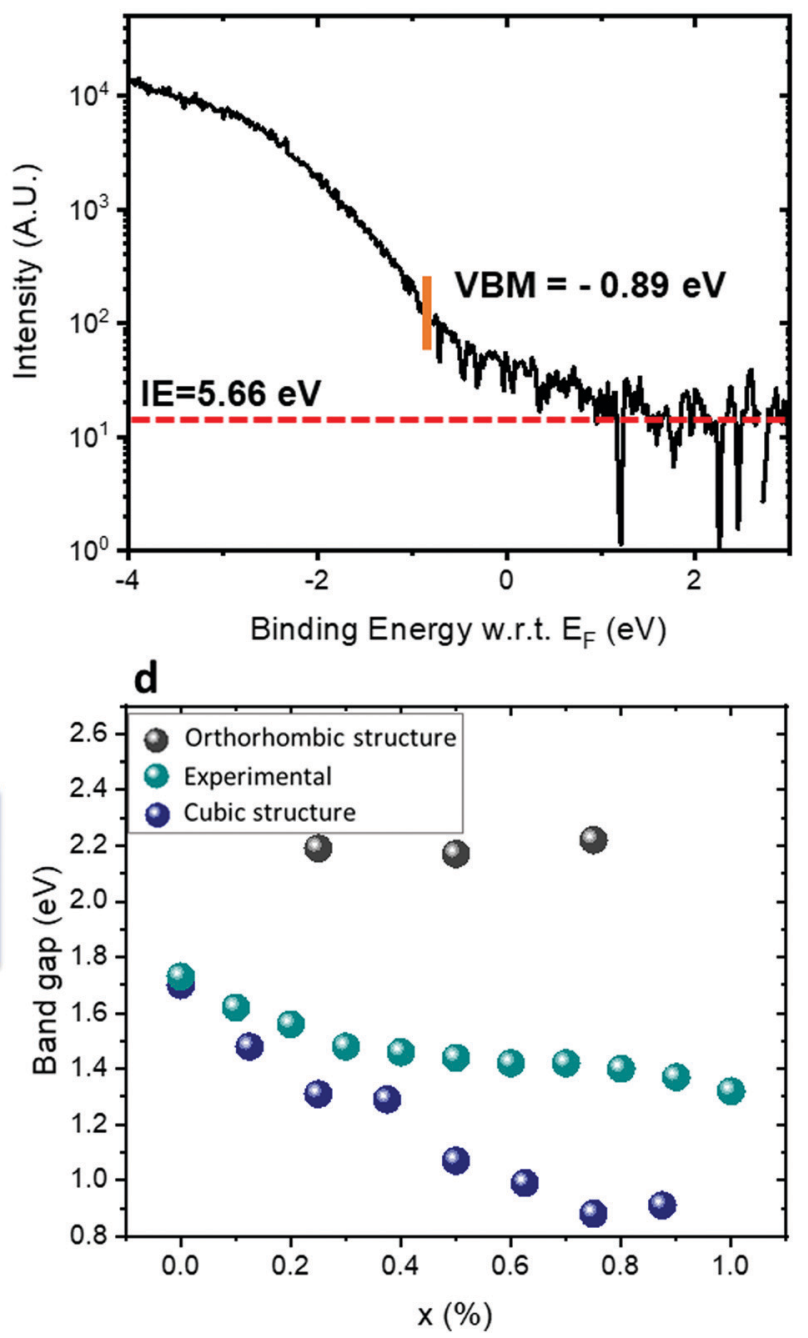

Fig. 5 (a) Photoemission cut-off measured via UPS for $\mathrm{CsSn}_{0.2} \mathrm{~Pb}_{0.8} \mathrm{I}_{2.6} \mathrm{Br}_{0.4}$. (b) The position of the VBM and ionization energy (IE) for $\left.\mathrm{CsSn}_{0.2} \mathrm{~Pb}_{0.8}\right|_{2.6} \mathrm{Br}_{0.4}$ measured by UPS. (c) Energy diagram of the different materials used in this study. The band gap of $\mathrm{CsPb}{ }_{3}$ is relatively wide with respect to the literature value, ${ }^{62}$ which is due to degradation as discussed in the text. (d) Experimental results and theoretical calculation of the band gaps for the various ratios when adding $\mathrm{SnBr}_{2} . X$ represents the ratio $\mathrm{Pb}: \mathrm{Sn}$.

halide ( $n \mathrm{p})$ orbitals. The lower binding energy of the Sn $5 \mathrm{~s}$ orbitals compared to the $\mathrm{Pb} 6 \mathrm{~s}$ orbitals upshifts the VBM with increasing Sn content, which is consistent with the experimental results. The CBM is derived from the hybridization of the antibonding $\mathrm{Pb}(6 \mathrm{p})$ and/or $\mathrm{Sn}(5 \mathrm{p})$ state and the halide ( $n \mathrm{p})$ orbitals with major contributions from $\mathrm{Pb}(6 \mathrm{p})$ and/or $\mathrm{Sn}(5 \mathrm{p})$. Some reports suggest that the CBM of the $\mathrm{Pb}-\mathrm{Sn}$ alloy is mainly composed of $\mathrm{Pb} 6 \mathrm{p}$ and $\mathrm{I} 5 \mathrm{p}$ orbitals since the binding energy of the $\mathrm{Sn} 5 \mathrm{p}$ orbital is lower than that of the $\mathrm{Pb} 5 \mathrm{p}$ orbital. ${ }^{60}$ The addition of $\mathrm{Sn}$ and $\mathrm{Br}$ in the mixed perovskites reduces the lattice constant and thus enhances the hybridization, which pushes the CBM to higher energy. ${ }^{61}$ Fig. $5 \mathrm{~d}$ shows the experimental and calculated band gaps for the different ratios. Density functional theory (DFT) was used for the band gap calculations (see more details in the Experimental section). The experimental band gaps are in between the calculated band gaps for the cubic structure and the orthorhombic structure.
It can be suggested that our different films have a mix of cubic and orthorhombic structures. For a low amount of Sn, the cubic structure is dominant, but when the Sn amount increases the orthorhombic structure (which is a metastable phase) starts to appear. Since the orthorhombic structure is inactive in solar cells, it influences the PV results as is discussed below.

Based on our chemical and physical characterizations, we introduced several perovskites with different ratios of $\mathrm{Pb}: \mathrm{Sn}$ into solar cells. We investigated three ratios of $\mathrm{Pb}: \mathrm{Sn}-80: 20$, $70: 30$ and 60:40 - using PTAA (poly[bis(4-phenyl)(2,4,6-trimethylphenyl)amine]) as the hole transport material, as presented in Fig. 6b. Fig. 6a shows an SEM cross section of the discussed solar cell, where the different layers can be observed clearly.

The solar cell structure is based on mesoporous $\mathrm{TiO}_{2}$, on which the Cs-based perovskite is deposited. To our knowledge, there is to date no report on the black phase of $\mathrm{CsPbI}_{3}$ on a 
a

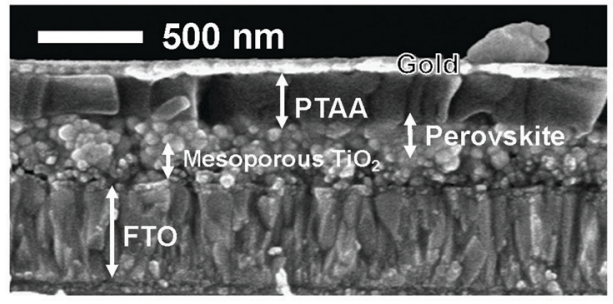

b

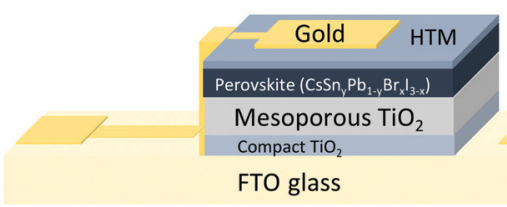

C

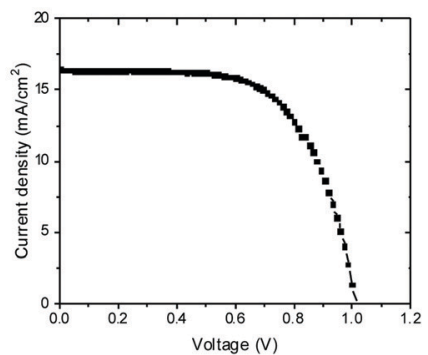

Fig. 6 (a) Cross section SEM image of the PSC with a ratio of $80: 20$ (CsSn $\left.0.2 \mathrm{~Pb}_{0.8} \mathrm{I}_{2.6} \mathrm{Br}_{0.4}\right)(\mathrm{Pb}: \mathrm{Sn}$ ) and PTAA as the HTM. (b) Schematic illustration of the perovskite solar cell configuration used in this work. (c) JV curve of the champion cell presenting $12.7 \%$ efficiency, a FF of $64.2 \%$, a $\mathrm{J}_{\mathrm{sc}}$ of $19.09 \mathrm{~mA} \mathrm{~cm}^{-2}$ and a $V_{o c}$ of $1 \mathrm{~V}$.

Table 2 Best PV parameters and average PV parameters (in brackets) for different ratios of $\mathrm{Pb}: \mathrm{Sn}$. Average of 20 cells

\begin{tabular}{lllll}
$\begin{array}{l}\mathrm{Pb}: \mathrm{Sn} \\
\text { ratio }\end{array}$ & $V_{\mathrm{oc}}[\mathrm{V}]$ & $J_{\mathrm{sc}}\left[\mathrm{mA} \mathrm{cm}^{-2}\right]$ & Fill factor $[\%]$ & PCE $[\%]$ \\
\hline $80: 20$ & 1.00 & 19.09 & 64.27 & 12.70 \\
& $(0.95 \pm 0.03)$ & $(18.71 \pm 0.47)$ & $(62 \pm 1.47)$ & $(10.10 \pm 0.23)$ \\
$70: 30$ & 0.84 & 13.84 & 44.25 & 4.60 \\
& $(0.83 \pm 0.01)$ & $(13.01 \pm 0.12)$ & $(43.17 \pm 1.02)$ & $(4.11 \pm 0.24)$ \\
$60: 40$ & 0.78 & 7.49 & 41.44 & 2.79 \\
& $(0.77 \pm 0.04)$ & $(6.85 \pm 1.47)$ & $(39.58 \pm 1.47)$ & $(2.01 \pm 0.02)$
\end{tabular}

mesoporous layer. Most reports show the black $\mathrm{CsPbI}_{3}$ perovskite phase in the planar configuration (compact $\mathrm{TiO}_{2}$ or PEDOT:PSS). ${ }^{63,64}$

The HOMO and LUMO levels of PTAA are shown in the supporting information (Fig. S10, ESI $\dagger$ ). When the $\mathrm{Pb}$ amount is larger, the PV performance is better, except for the pure $\mathrm{CsPbI}_{3}$, which is highly unstable (Table 2). The experimental and calculated band gaps show that as the Sn concentration increases inside the perovskite, the orthorhombic structure becomes dominant. This phase is inactive for PV solar cells and therefore reduces the PV parameters. The $60: 40$ ratio of $\mathrm{Pb}$ : Sn gives the worst PV performance. This is the result of the orthorhombic structure but is also due to two structures formed in this case, the $\mathrm{CsPbI}_{3}$ and the $\mathrm{CsSnI}_{3}$ perovskites. Therefore, the physical and electronic properties are not optimal to function as an efficient light harvester in the solar cell. On the other hand, in the case of an $80: 20 \mathrm{~Pb}: \mathrm{Sn}$ ratio the PV performance was the highest, achieving a $12.7 \%$ power conversion efficiency (see Fig. 6c and Table 2), which is one of the highest PCEs reported for similar perovskite compositions. Forward and reverse scans of the $I V$ curve (Fig. S11, ESI $\dagger$ ) show minimal hysteresis for these cells.

The stability of the full solar cells was studied under different conditions, as presented in Fig. 7a and b. The stability measurements presented in Fig. 7a were performed under continuous 1 sun illumination (the corresponding other PV parameters of these cells are presented in Fig. S12a-c, ESI $\dagger$ ). An increase in the PV performance can be observed in the first 4 to 10 hours of continuous illumination for all $\mathrm{Pb}: \mathrm{Sn}$ ratios. Following that, the PV performance of the cells decreases in all cases. Table S1 (ESI $\dagger$ ) shows the change in the PV parameters, a

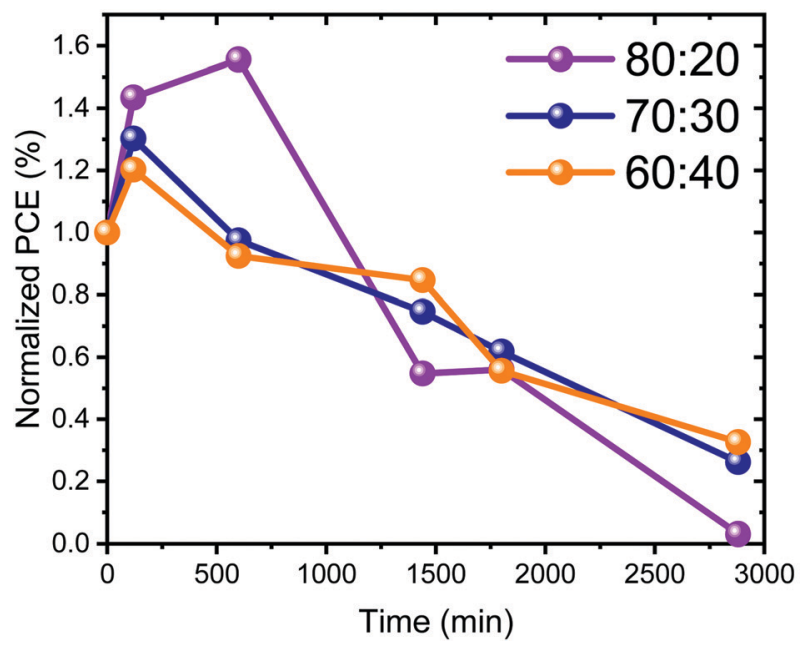

b

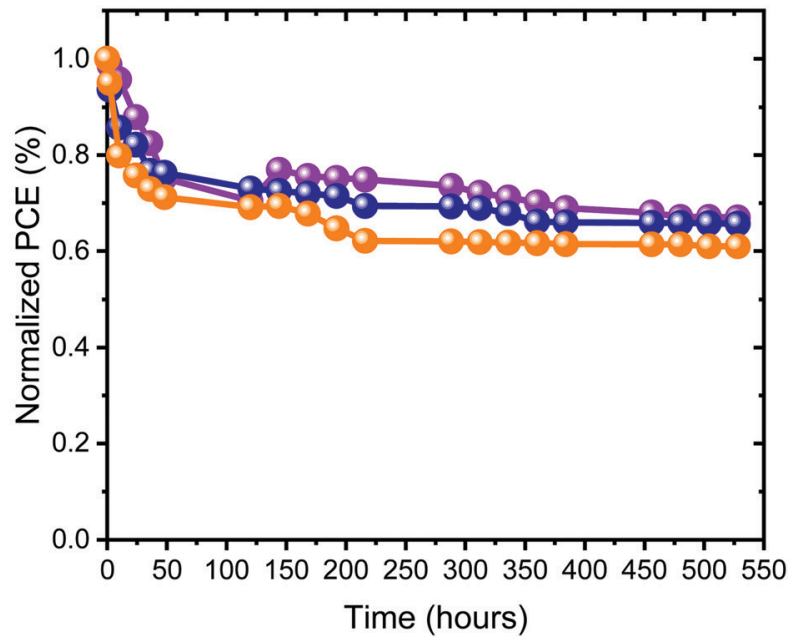

Fig. 7 (a) Stability under 1 sun illumination of complete solar cells with different ratios of Pb: Sn as discussed in this work. (b) Stability of the cells stored under an inert atmosphere and measured in the open air with encapsulation. 
before illumination and after reaching the highest PV performance. The change in the PV parameters is the largest for the $80: 20$ ratio. Introducing more Sn into the perovskite leads to smaller changes in the PV parameters during continuous illumination. The increase of the PV parameters upon continuous illumination shows the sensitivity of those perovskite compositions to light, as also discussed throughout this work. Fig. 7b and Fig. S12d-f (ESI $\dagger$ ) show the stability of the cells stored under an inert atmosphere, where the $J-V$ curves were measured in air. In the beginning (45-50 hours) there is a drop in the PV performance for all ratios. Thereafter, the PV performance remains stable for 400 hours. To summarize, the complete solar cells degraded under continuous illumination (after an initial increase), similar to the photostability of the films with the same composition (same $\mathrm{Pb}: \mathrm{Sn}$ ratios), as presented in Fig. 2b. Still the full cells are slightly less stable than the films, which is probably due to the additional HTM and the measurement conditions.

\section{Conclusion}

In this work, $\mathrm{CsSn}_{y} \mathrm{~Pb}_{1-y} \mathrm{Br}_{x} \mathrm{I}_{3-x}$ all inorganic perovskites were synthesized at various ratios of $\mathrm{Pb}: \mathrm{Sn}$. Stability and photostability measurements show that $\mathrm{Sn}$ stabilizes the $\mathrm{CsPbI}_{3}$ black PV active phase. The Cs cation shrinks the cubic structure and as a result slows down the oxidation of $\mathrm{Sn}$. The Hall effect measurement shows an increase in the mobility and in the charge carrier density with the addition of Sn to the structure. UPS reveals an upward shift of the VBM and a small increase in the CBM, which provide a decrease in the band gap with the increase of the Sn amount in the structure. Finally, these compounds were introduced into mesoporous material based perovskite solar cells, achieving $12.7 \%$ power conversion efficiency. As the Sn amount increases, the PV performance decreases due to phase mixing of the active cubic phase and the nonactive orthorhombic phase supported by DFT calculations.

\section{Experimental section}

\section{Film fabrication}

Microscope glass was cleaned with ethanol and acetone. Oxygen plasma treatment ( $80 \%$ power, Diener) was performed before deposition of the perovskite solution.

\section{Device fabrication}

$\mathrm{SnO}_{2} /$ (FTO) conductive glass (10 $\mathrm{Ohm} \mathrm{cm}^{-1}$, Pilkington) was etched by the reaction of zinc powder with $\mathrm{HCl}$ (37\% Sigma) on top of the glass. After etching, the glass was cleaned in a sonication bath for 15 minutes followed by oxygen plasma treatment $\left(80 \%\right.$ power, Diener). The compact $\mathrm{TiO}_{2}$ (TiDIP, 75\% in isopropanol, Aldrich, diluted 1:5 in isopropanol) layer was deposited on the substrate by spin coating (5000 rpm for 30 seconds), followed by deposition of $\mathrm{m}-\mathrm{TiO}_{2}$ nanoparticles (30-NRD, dyesol) $(1: 6 \mathrm{w} / \mathrm{w} \%$ in ethanol absolute) by spincoating (5000 rpm for 30 seconds); then the substrate was annealed at $450{ }^{\circ} \mathrm{C}$ for $30 \mathrm{~min}$. $\mathrm{TiCl}_{4}$ was applied on the $\mathrm{m}-\mathrm{TiO}_{2}$ film.

For the perovskite deposition, $60 \mu \mathrm{l}$ of perovskite solution was dropped on the middle of the substrate, followed by a spincoating process with a five second delay time, ten second spin at $1000 \mathrm{rpm}$, and 45 second spin at $5000 \mathrm{rpm}$. 25 seconds before the end of the spin coating, $50 \mu$ of toluene was added dropwise onto the substrate. The cells were annealed at $110{ }^{\circ} \mathrm{C}$ for two minutes. Next, the PTAA film was deposited: a PTAA (Ossila)/toluene $(15 \mathrm{mg} / 1 \mathrm{ml})$ solution with $13.6 \mathrm{ml}$ of Li-bis(trifluoromethanesulfonyl) imide (Li-TFSI)/acetonitrile $(28.3 \mathrm{mg} / 1 \mathrm{ml}$ ) and $6.8 \mathrm{ml} \mathrm{TBP}$ added was spin-coated at $3000 \mathrm{rpm}$ for 30 seconds and annealed at $75{ }^{\circ} \mathrm{C}$ for five minutes. Finally, a $70 \mathrm{~nm}$ thick gold electrode was thermally evaporated on the film under a vacuum of $\sim 10^{-7}$ Torr.

\section{Preparation of perovskite solutions}

The perovskite solutions were prepared in a nitrogen filled glovebox $\mathrm{H}_{2} \mathrm{O}<0.1 \mathrm{ppm}$ and $\mathrm{O}_{2}<5.0 \mathrm{ppm}$. All of the inorganic precursors were purchased from Sigma Aldrich. A $\operatorname{CsSn}_{y} \mathrm{~Pb}_{1-y} \mathrm{Br}_{x} \mathrm{I}_{3-x}$ (different ratios) solution of $0.48 \mathrm{M}$ was prepared by dissolving CsI, $\mathrm{PbI}_{2}$, and $\mathrm{SnBr}_{2}$ in a mixture of dimethylformamide: dimethyl sulfoxide (DMF/DMSO) (85\%:15\%). A $\mathrm{CsSnI}_{3}$ solution (0.48 M) was prepared by dissolving CsI, $\mathrm{PbI}_{2}$, and $\mathrm{SnI}_{2}$ in a mixture of dimethylformamide : dimethyl sulfoxide (DMF/DMSO) (85\%:15\%). The perovskite solutions were prepared 12 hours before the perovskite deposition.

\section{Encapsulation}

Encapsulation was done with a Meltonix 1170-60 (Solaronix) and cover glasses (PAUL MARIENFELD) in a nitrogen environment.

\section{Absorbance measurements}

Absorbance measurements were performed using a Jasco V-670 spectrophotometer.

\section{X-ray diffraction (XRD)}

$\mathrm{X}$-ray powder diffraction measurements were performed in grazing incidence X-ray diffraction (GIXRD) mode on a D-8 Advance diffractometer (Bruker AXS, Karlsruhe, Germany) with a goniometer radius of $217.5 \mathrm{~mm}$, a secondary graphite monochromator, $2^{\circ}$ Soller slits and a $0.2 \mathrm{~mm}$ receiving slit. XRD patterns within the range $2^{\circ}$ to $60^{\circ}(2 \theta)$ were taken at $273 \mathrm{~K}$ using CuK $\alpha$ radiation $(\lambda 1.5418 \AA)$ with the following measurement conditions: a tube voltage of $40 \mathrm{kV}$, a tube current of $40 \mathrm{~mA}$, step-scan mode with a step size of $0.02^{\circ}(2 \theta)$ and a counting time of $1 \mathrm{~s}^{-3} \mathrm{~s}$ per step. The value of the grazing incidence angle was $2.5^{\circ}$.

Ultra high resolution scanning electron microscopy (UHR-SEM)

The images were attained by using a Sirion UHR SEM of FEI (Field Emission Instruments). The measurement conditions were $5 \mathrm{kV}$, the spot size was 3.0, and the detector was TLS. 


\section{Hall effect}

Hall effect measurements were made using a Lake Shore dc Hall effect system model 8404. A magnetic field of $1.7 \mathrm{~T}$, and a current of $100 \mathrm{nA}$ were used in the measurement. The samples were illuminated with 0.25 sun of a white LED source. Each measurement was conducted 20 times, and the average results and the standard deviations were used in the calculation of the final values. Also, in these measurements we used the high resistivity option in order to achieve reliable results.

\section{Ultraviolet photoelectron spectroscopy (UPS)}

UPS measurements were performed in an ultrahigh vacuum at room temperature. He I photons $(21.22 \mathrm{eV})$ generated by a discharge lamp were used to probe the work function and valence band edges.

\section{Photovoltaic characterization}

Photovoltaic measurements were performed using a Newport system, composed of an Oriel $I-V$ test station using an Oriel Sol3A simulator. The solar simulator is class AAA for spectral performance, uniformity of irradiance, and temporal stability. The solar simulator is equipped with a $450 \mathrm{~W}$ xenon lamp. The output power is adjusted to match AM1. The spectrally matched classic cations are IEC60904-9 2007, JIC C 8912, and ASTM E927-05.

\section{DFT calculations}

The density functional theory (DFT) calculations of the band gaps were performed with the Quantum ESPRESSO code, ${ }^{65}$ using a plane-wave basis and norm-conserving pseudopotentials for the atomic cores. The Perdew-Burke-Ernzerhof parametrization of the exchange-correlation functional was chosen. Spinorbit coupling was not included, because its effect on the bandgaps in perovskites is balanced by neglecting the selfinteraction correction (see Table 5 in ref. 66).

The doped crystals were calculated using 40-atom supercells, which were eight times larger than the elementary cubic cell (four atoms) and two times larger than the elementary orthorhombic cell (20 atoms). A uniform $k$-mesh of $4 \times 4 \times 4$ points in the Brillouin zone was used for the supercells, and a two times larger grid for the pure compounds.

\section{Conflicts of interest}

There are no conflicts to declare.

\section{Acknowledgements}

This research was supported by the Israel Science Foundation grant No. 937/18 and 2552/17. Calculations were performed using the PL-GRID infrastructure (Prometheus computer and supported by the National Science Centre in Poland (grant 2019/33/B/ST8/02105)). Work in Princeton was supported by the US-Israel Binational Science Foundation (BSF Grant No. 2018349).

\section{References}

1 C. R. Kagan, D. B. Mitzi and C. D. Dimitrakopoulos, Science, 1999, 286, 945-947.

2 Y. Fu, H. Zhu, J. Chen, M. P. Hautzinger, X. Y. Zhu and S. Jin, Nat. Rev. Mater., 2019, 4, 169-188.

3 J. Shamsi, A. S. Urban, M. Imran, L. De Trizio and L. Manna, Chem. Rev., 2019, 119, 3296-3348.

4 W. J. Nimens, S. J. Lefave, L. Flannery, J. Ogle, D.-M. Smilgies, M. T. Kieber-Emmons and L. Whittaker-Brooks, Angew. Chem., Int. Ed., 2019, 58, 13912-13921.

5 G. E. Eperon, S. N. Habisreutinger, T. Leijtens, B. J. Bruijnaers, J. J. van Franeker, D. W. deQuilettes, S. Pathak, R. J. Sutton, G. Grancini, D. S. Ginger, R. A. J. Janssen, A. Petrozza and H. J. Snaith, ACS Nano, 2015, 9, 9380-9393.

6 Q. Wang, B. Chen, Y. Liu, Y. Deng, Y. Bai, Q. Dong and J. Huang, Energy Environ. Sci., 2017, 10, 516-522.

7 X. Li, M. Ibrahim Dar, C. Yi, J. Luo, M. Tschumi, S. M. Zakeeruddin, M. K. Nazeeruddin, H. Han and M. Grätzel, Nat. Chem., 2015, 7, 703-711.

8 G. Abdelmageed, L. Jewell, K. Hellier, L. Seymour, B. Luo, F. Bridges, J. Z. Zhang and S. Carter, Appl. Phys. Lett., 2016, 109, 233905.

9 N. Chander, A. F. Khan, P. S. Chandrasekhar, E. Thouti, S. K. Swami, V. Dutta and V. K. Komarala, Appl. Phys. Lett., 2014, 105, 033904.

10 F. Yang, D. Hirotani, G. Kapil, M. A. Kamarudin, C. H. Ng, Y. Zhang, Q. Shen and S. Hayase, Angew. Chem., 2018, 130, 12927-12931.

11 S. Xiang, W. Li, Y. Wei, J. Liu, H. Liu, L. Zhu and H. Chen, Nanoscale, 2018, 10, 9996-10004.

12 Y. Liang, L. Guan, X. Xu, S. Han, J. Guo, J. Wang, X. Chen, Z. Zhang and X. Li, J. Phys. Chem. C, 2020, 124, 6028-6037.

13 A. Swarnkar, W. J. Mir and A. Nag, ACS Energy Lett., 2018, 3, 286-289.

14 Y. Wu, F. Xie, H. Chen, X. Yang, H. Su, M. Cai, Z. Zhou, T. Noda and L. Han, Adv. Mater., 2017, 29, 1701073.

15 K. Pinsuwan, C. Boonthum, T. Supasai, S. Sahasithiwat, P. Kumnorkaew and P. Kanjanaboos, J. Mater. Sci., 2020, 55, 3484-3494.

16 E. V. Péan, C. S. De Castro and M. L. Davies, Mater. Lett., 2019, 243, 191-194.

17 D. A. Gidlow, Occup. Med., 2004, 54, 76-81.

18 G. Flora, D. Gupta and A. Tiwari, Interdiscip. Toxicol., 2012, 5, 47-58.

19 R. A. Goyer, Environ. Health Perspect., 1993, 100, 177-187.

20 F. Li and M. Liu, J. Mater. Chem. A, 2017, 5, 15447-15459.

21 G. E. Eperon, G. M. Paternò, R. J. Sutton, A. Zampetti, A. A. Haghighirad, F. Cacialli and H. J. Snaith, J. Mater. Chem. A, 2015, 3, 19688-19695.

22 J. K. Nam, S. U. Chai, W. Cha, Y. J. Choi, W. Kim, M. S. Jung, J. Kwon, D. Kim and J. H. Park, Nano Lett., 2017, 17, 2028-2033.

23 M. Saliba, T. Matsui, J.-Y. Seo, K. Domanski, J.-P. CorreaBaena, M. K. Nazeeruddin, S. M. Zakeeruddin, W. Tress, A. Abate, A. Hagfeldt and M. Grätzel, Energy Environ. Sci., 2016, 9, 1989-1997. 
24 C. Liu, W. Li, H. Li, H. Wang, C. Zhang, Y. Yang, X. Gao, Q. Xue, H.-L. Yip, J. Fan, R. E. I. Schropp and Y. Mai, Adv. Energy Mater., 2019, 9, 1803572.

25 W. Xiang, Z. Wang, D. J. Kubicki, W. Tress, J. Luo, D. Prochowicz, S. Akin, L. Emsley, J. Zhou, G. Dietler, M. Grätzel and A. Hagfeldt, Joule, 2019, 3, 205-214.

26 T. Zhang, M. I. Dar, G. Li, F. Xu, N. Guo, M. Grätzel and Y. Zhao, Sci. Adv., 2017, 3, e1700841.

27 A. Marronnier, G. Roma, S. Boyer-Richard, L. Pedesseau, J.-M. Jancu, Y. Bonnassieux, C. Katan, C. C. Stoumpos, M. G. Kanatzidis and J. Even, ACS Nano, 2018, 12, 3477-3486.

28 A. Shpatz Dayan, B.-E. Cohen, S. Aharon, C. Tenailleau, M. Wierzbowska and L. Etgar, Chem. Mater., 2018, 30, 8017-8024.

29 F. O. Saouma, C. C. Stoumpos, J. Wong, M. G. Kanatzidis and J. I. Jang, Nat. Commun., 2017, 8, 742.

30 A. K. Jena, A. Kulkarni, Y. Sanehira, M. Ikegami and T. Miyasaka, Chem. Mater., 2018, 30, 6668-6674.

31 H. Zhao, J. Xu, S. Zhou, Z. Li, B. Zhang, X. Xia, X. Liu, S. Dai and J. Yao, Adv. Funct. Mater., 2019, 29, 1808986.

32 T. Fujihara, S. Terakawa, T. Matsushima, C. Qin, M. Yahiro and C. Adachi, J. Mater. Chem. C, 2017, 5, 1121-1127.

33 W. Ke, C. C. Stoumpos, I. Spanopoulos, L. Mao, M. Chen, M. R. Wasielewski and M. G. Kanatzidis, J. Am. Chem. Soc., 2017, 139, 14800-14806.

34 G. C. Papavassiliou and I. B. Koutselas, Synth. Met., 1995, 71, 1713-1714.

35 C. C. Stoumpos, C. D. Malliakas and M. G. Kanatzidis, Inorg. Chem., 2013, 52, 9019-9038.

36 E. J. W. Whittaker and R. Muntus, Geochim. Cosmochim. Acta, 1970, 34, 945-956.

37 G. Kieslich, S. Sun and A. K. Cheetham, Chem. Sci., 2014, 5, 4712-4715.

38 Z. Li, M. Yang, J. S. Park, S. H. Wei, J. J. Berry and K. Zhu, Chem. Mater., 2016, 28, 284-292.

39 M. Deepa, M. Salado, L. Calio, S. Kazim, S. M. Shivaprasad and S. Ahmad, Phys. Chem. Chem. Phys., 2017, 19, 4069-4077.

40 D. Sabba, H. K. Mulmudi, R. R. Prabhakar, T. Krishnamoorthy, T. Baikie, P. P. Boix, S. Mhaisalkar and N. Mathews, J. Phys. Chem. C, 2015, 119, 1763-1767.

41 I. Chung, B. Lee, J. He, R. P. H. Chang and M. G. Kanatzidis, Nature, 2012, 485, 486-489.

42 N. Wang, Y. Zhou, M.-G. Ju, H. F. Garces, T. Ding, S. Pang, X. C. Zeng, N. P. Padture and X. W. Sun, Adv. Energy Mater., 2016, 6, 1601130.

43 H. Xu, J. Duan, Y. Zhao, Z. Jiao, B. He and Q. Tang, J. Power Sources, 2018, 399, 76-82.

44 B. Li, R. Long, Y. Xia and Q. Mi, Angew. Chem., Int. Ed., 2018, 57, 13154-13158.

45 F. Reyes-Pérez, J. J. Gallardo, T. Aguilar, R. Alcántara, C. Fernández-Lorenzo and J. Navas, ChemistrySelect, 2018, 3, 10226-10235.

46 S. Liu, L. Yuan, Y. Zhao, Y. Chen, W. Xiang and X. Liang, J. Alloys Compd., 2019, 806, 1022-1028.
47 J. Liang, P. Zhao, C. Wang, Y. Wang, Y. Hu, G. Zhu, L. Ma, J. Liu and Z. Jin, J. Am. Chem. Soc., 2017, 139, 14009-14012.

48 N. Li, Z. Zhu, J. Li, A. K.-Y. Jen and L. Wang, Adv. Energy Mater., 2018, 8, 1800525.

49 J. L. Knutson, J. D. Martin and D. B. Mitzi, Inorg. Chem., 2005, 44, 4699-4705.

50 A. Goyal, S. McKechnie, D. Pashov, W. Tumas, M. Van Schilfgaarde and V. Stevanović, Chem. Mater., 2018, 30, 3920-3928.

51 T. Leijtens, R. Prasanna, A. Gold-Parker, M. F. Toney and M. D. McGehee, ACS Energy Lett., 2017, 2, 2159-2165.

52 R. K. Misra, L. Ciammaruchi, S. Aharon, D. Mogilyansky, L. Etgar, I. Visoly-Fisher and E. A. Katz, ChemSusChem, 2016, 9, 2572-2577.

53 M. Zhang, M. Ye, W. Wang, C. Ma, S. Wang, Q. Liu, T. Lian, J. Huang and Z. Lin, Adv. Mater., 2020, 32, 2000999.

54 X. D. Zhu, Y. Xie and Y. T. Liu, J. Mater. Chem. A, 2018, 6, 21255-21260.

55 Y. Takahashi, H. Hasegawa, Y. Takahashi and T. Inabe, J. Solid State Chem., 2013, 205, 39-43.

56 C. Wehrenfennig, G. E. Eperon, M. B. Johnston, H. J. Snaith and L. M. Herz, Adv. Mater., 2014, 26, 1584-1589.

57 G. Xing, N. Mathews, S. Sun, S. S. Lim, Y. M. Lam, M. Gratzel, S. Mhaisalkar and T. C. Sum, Science, 2013, 342, 344-347.

58 A. Miyata, A. Mitioglu, P. Plochocka, O. Portugall, J. T. W. Wang, S. D. Stranks, H. J. Snaith and R. J. Nicholas, Nat. Phys., 2015, 11, 582-587.

59 L. Ji, X. Zhang, T. Zhang, Y. Wang, F. Wang, Z. Zhong, Z. D. Chen, Z. Xiao, L. Chen and S. Li, J. Mater. Chem. A, 2019, 7, 9154-9162.

60 F. Hao, C. C. Stoumpos, D. H. Cao, R. P. H. Chang and M. G. Kanatzidis, Nat. Photonics, 2014, 8, 489-494.

61 V. K. Ravi, G. B. Markad and A. Nag, ACS Energy Lett., 2016, 1, 665-671.

62 C. Liu, M. Hu, X. Zhou, J. Wu, L. Zhang, W. Kong, X. Li, X. Zhao, S. Dai, B. Xu and C. Cheng, NPG Asia Mater., 2018, 10, 552-561.

63 Y. Hu, F. Bai, X. Liu, Q. Ji, X. Miao, T. Qiu and S. Zhang, ACS Energy Lett., 2017, 2, 2219-2227.

64 F. Haque, M. Wright, M. A. Mahmud, H. Yi, D. Wang, L. Duan, C. Xu, M. B. Upama and A. Uddin, ACS Omega, 2018, 3, 11937-11944.

65 P. Giannozzi, S. Baroni, N. Bonini, M. Calandra, R. Car, C. Cavazzoni, D. Ceresoli, G. L. Chiarotti, M. Cococcioni, I. Dabo, A. Dal Corso, S. De Gironcoli, S. Fabris, G. Fratesi, R. Gebauer, U. Gerstmann, C. Gougoussis, A. Kokalj, M. Lazzeri, L. Martin-Samos, N. Marzari, F. Mauri, R. Mazzarello, S. Paolini, A. Pasquarello, L. Paulatto, C. Sbraccia, S. Scandolo, G. Sclauzero, A. P. Seitsonen, A. Smogunov, P. Umari and R. M. Wentzcovitch, J. Phys.: Condens. Matter, 2009, 21, 395502.

66 M. Wierzbowska, J. J. Meléndez and D. Varsano, Comput. Mater. Sci., 2018, 142, 361-371. 